\title{
Influence of stoichiometry on indentation-induced plasticity in CuZr glasses
}

\author{
Karina E. Avila ${ }^{1,2} \cdot$ Stefan Küchemann ${ }^{1,2} \cdot$ Reinhardt E. Pinzón $^{3,4,5} \cdot$ Herbert M. Urbassek $^{1,2}$ (D)
}

Received: 3 August 2021 / Accepted: 9 August 2021 / Published online: 23 August 2021

(c) The Author(s) 2021

\begin{abstract}
Plasticity in metallic glasses depends on their stoichiometry. We explore this dependence by molecular dynamics simulations for the case of $\mathrm{CuZr}$ alloys using the compositions $\mathrm{Cu}_{64.5} \mathrm{Zr}_{35.5}, \mathrm{Cu}_{50} \mathrm{Zr}_{50}$, and $\mathrm{Cu}_{35.5} \mathrm{Zr}_{64.5}$. Plasticity is induced by nanoindentation and orthogonal cutting. Only the $\mathrm{Cu}_{64.5} \mathrm{Zr}_{35.5}$ sample shows the formation of localized strain in the form of shear bands, while plasticity is more homogeneous for the other samples. This feature concurs with the high fraction of full icosahedral short-range order found for $\mathrm{Cu}_{64.5} \mathrm{Zr}_{35.5}$. In all samples, the atomic density is reduced in the plastic zone; this reduction is accompanied by a decrease of the average atom coordination, with the possible exception of $\mathrm{Cu}_{35.5} \mathrm{Zr}_{64.5}$, where coordination fluctuations are high. The strongest density reduction occurs in $\mathrm{Cu}_{64.5} \mathrm{Zr}_{35.5}$, where it is connected with the partial destruction of full icosahedral short-range order. The difference in plasticity mechanism influences the shape of the pileup and of the chip generated by nanoindentation and cutting, respectively.
\end{abstract}

Keywords Metallic glass $\cdot$ Plasticity $\cdot$ Indentation $\cdot$ Shear bands $\cdot$ Molecular dynamics

\section{Introduction}

The mechanical properties of metallic glasses (MGs) are sensitive to the processing history $[1,2]$ and also to their atomic composition. This is due to the formation of

Herbert M. Urbassek

urbassek@rhrk.uni-kl.de

http://www.physik.uni-kl.de/urbassek/

Reinhardt E. Pinzón

reinhardt.pinzon@utp.ac.pa

http://hpc-simulations.utp.ac.pa/

1 Physics Department, University Kaiserslautern,

Erwin-Schrödinger-Straße, D-67663 Kaiserslautern,

Germany

2 Research Center OPTIMAS, University Kaiserslautern, Erwin-Schrödinger-Straße, D-67663 Kaiserslautern, Germany

3 Centro de Investigaciones Hidráulicas e Hidrotécnicas (CIHH), Universidad Tecnológica de Panamá (UTP), P.O. Box 0819-07289, Panamá City, Panamá

4 Sistema Nacional de Investigación (SNI), SENACYT, Panama City, Panamá

5 Centro de Estudios Multidisciplinarios de Ingeniería Ciencias y Tecnología (CEMCIT-AIP), P.O. Box 0819-07289, El Dorado, Panamá, República de Panamá short-range order (SRO) motifs that are strictly linked to the preparation method [3-5] and to the stoichiometry [4, 6-8]. As most relevant motif, the so-called full icosahedral (FI) clusters centered on $\mathrm{Cu}$ atoms have been identified [3]. The presence of this type of polyhedra effectively reduces the free volume between the atoms and thus has been related to the formation of more stable MGs, i.e., more relaxed samples [5, 7-11].

The effects of variation in atomic composition have been studied in the CuZr MGs, and it has been shown that a composition with around $75 \% \mathrm{Cu}$ content forms the maximum number of FIs [7, 8]. Increasing the $\mathrm{Cu}$ content results in a higher Young's modulus and yield strength [8]. However, in such compositions, the plastic flow is reduced by the rapid formation and propagation of shear bands [12-15]. Thus, compositions with $\mathrm{Cu}$ content $>50 \%$ are preferred to study the shear-band phenomenon in MGs [16-19].

In the present work, we study the plasticity in three compositions of $\mathrm{CuZr} \mathrm{MG}$, namely $\mathrm{Cu}_{64.5} \mathrm{Zr}_{35.5}, \mathrm{Cu}_{50} \mathrm{Zr}_{50}$, and $\mathrm{Cu}_{35.5} \mathrm{Zr}_{64.5}$. Plasticity in the MGs is induced by simulated indentation. However, we show in the Appendix 1 that comparable results are obtained for another way of inducing plastic flow in the MGs, namely by orthogonal cutting of the samples. We analyse the local changes occurring in the polyhedral clusters present after machining the samples and 
find that most of the deformation occurs via the annihilation of the FIs for the samples containing a high fraction of $\mathrm{Cu}$. In the case of the sample with the smallest $\mathrm{Cu}$ concentration, the creation of polyhedra with coordination numbers 12 and 13 is observed.

\section{Simulation details}

Three different CuZr MG compositions were created by using the open-source code LAMMPS [20], namely $\mathrm{Cu}_{64.5}$ $\mathrm{Zr}_{35.5}, \mathrm{Cu}_{50} \mathrm{Zr}_{50}$, and $\mathrm{Cu}_{35.5} \mathrm{Zr}_{64.5}$. The interaction between the atoms is modeled via an embedded-atom-method potential [21]. The samples have approximate dimensions of $56 \mathrm{~nm} \times$ $22 \mathrm{~nm} \times 45 \mathrm{~nm}$ in the $x, y$, and $z$ directions, respectively (see Fig. 1), containing more than $3 \cdot 10^{6}$ atoms. For the preparation of the samples, a crystalline mixture of the appropriate stoichiometry is first heated to a temperature $T=2000 \mathrm{~K}$ for a time period of $500 \mathrm{ps}$. Then, the molten mixture is cooled down to a final temperature of $T=0.1 \mathrm{~K}$ at a rate of $0.01 \mathrm{~K} /$ ps. The cooling is performed under periodic boundary conditions using an isobaric ensemble with a Nose-Hoover thermostat. After cooling, the sample is relaxed with periodic boundary conditions for 200 ps. Subsequently, the boundary condition in the top surface is changed to a free boundary, and the samples are relaxed for an additional time of $300 \mathrm{ps}$ before indentation.

During indentation, a layer of 2.8-nm-width is fixed at the bottom of the samples to avoid any center-of-mass translation. Also, the temperature is kept fixed by using an NVT ensemble. The indenter has a cylindrical shape with a radius of $R=7 \mathrm{~nm}$; it is modeled by a repulsive potential [22] with a stiffness constant of $10 \mathrm{eV} / \AA^{3}$. Initially, the indenter is positioned just above the sample surface and

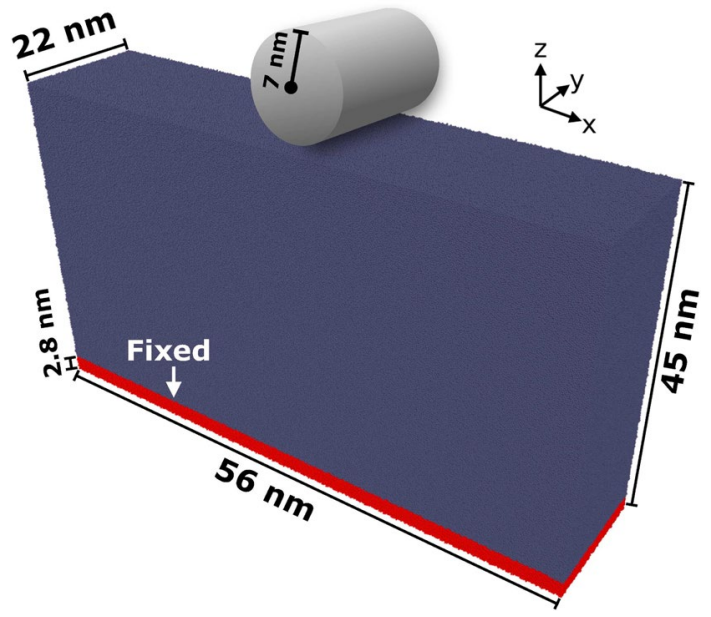

Fig. 1 Schematic setup of the nanoindentation simulations. then is moved in the $-z$ direction at a velocity of $20 \mathrm{~m} / \mathrm{s}$ to a total indentation depth of $7 \mathrm{~nm}$.

We use the open-source visualization tool (OVITO) [23] to calculate the atomic shear strain and to determined the polyhedral clusters characterizing the SRO in the samples.

\section{Results}

\subsection{Polyhedral clusters in the undeformed samples}

Before applying a deformation, we analyse which polyhedral clusters are present in our three different compositions, shown in Fig. 2. Polyhedral clusters are conveniently analyzed by the number of polygonal faces of the Voronoi polyhedron around the central atom; thus, icosahedral clusters are denoted as $\langle 0,0,12,0\rangle$, indicating that 0 triangular, quadrangular, or hexagonal faces are present besides the 12 pentagons defining the icosahedron. Fig. 2 provides the averages over $\mathrm{Cu}$-centered and $\mathrm{Zr}$-centered polyhedra in the samples. The figure shows that for the case of $\mathrm{Cu}_{64.5}$ $\mathrm{Zr}_{35.5}$, the FI clusters are the predominant type of the SRO motifs with a fraction of $16 \%$. In comparison, the percentage of FI clusters is significantly smaller in the compositions $\mathrm{Cu}_{50} \mathrm{Zr}_{50}$ and $\mathrm{Cu}_{35.5} \mathrm{Zr}_{64.5}$ with a fraction of $6 \%$ and $2 \%$, respectively. This is consistent with experiments [8] and previous simulations [7] where the maximum of pentagonal polyhedra was found for a $\mathrm{Cu}$ concentration of 75\%. Nonetheless, here these clusters are still the dominant type for the composition $\mathrm{Cu}_{50} \mathrm{Zr}_{50}$. In the case of the

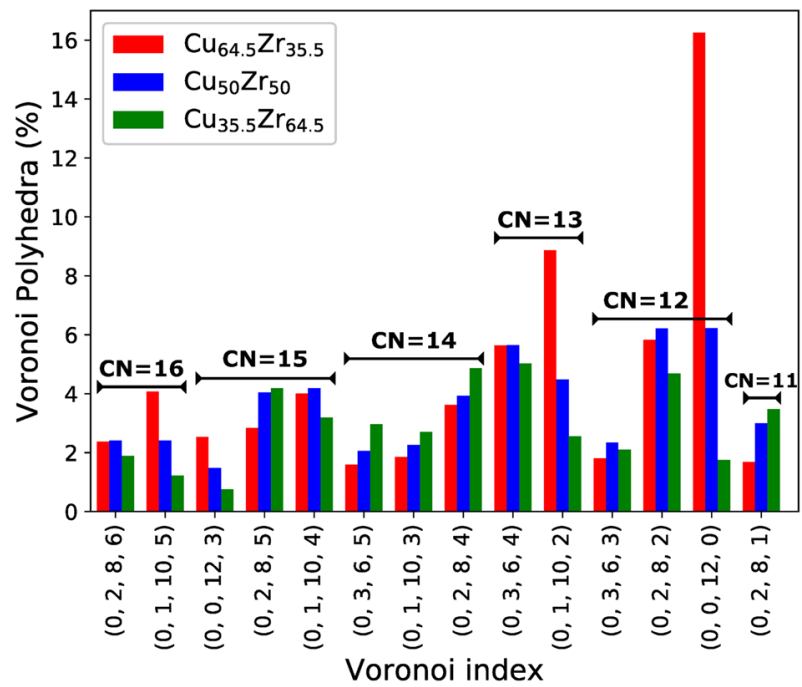

Fig. 2 List of the most frequent Voronoi polyhedra found in the three compositions. The coordination number $(\mathrm{CN})$ of the central atom in the cluster is indicated. 
composition $\mathrm{Cu}_{35.5} \mathrm{Zr}_{64.5}$, the most dominant clusters are the $\langle 0,2,8,4\rangle$ and $\langle 0,2,8,2\rangle$ polyhedra.

It is well known that local icosahedral ordering reduces both the local atomic volume and the potential energy of the central atom below that in an hcp or fcc environment [24]. Hence full icosahedral clusters $\langle 0,0,12,0\rangle$ are believed to be basic for the understanding of MGs, and we shall in the following discussion mostly focus on them. The overwhelming majority (99\% for $\mathrm{Cu}_{64.5} \mathrm{Zr}_{35.5}$ and $\mathrm{Cu}_{50} \mathrm{Zr}_{50}$ ) of icosahedra are $\mathrm{Cu}$-centered, since the atomic volume of $\mathrm{Cu}$ is smaller than that of Zr. As Ma [10] argues, small perturbations of the fully icosahedral structure can change the local order to $\langle 0,2,8,2\rangle$ or $\langle 0,3,6,3\rangle$; both motifs are amply found in Fig. 2.

Even for the $\mathrm{Cu}$-poor sample, $\mathrm{Cu}_{35.5} \mathrm{Zr}_{64.5}$, the number of pentagons in the nearest-neighbor shell is always dominant, Fig. 2, giving evidence of the non-periodic constitution of this material. $\mathrm{Zr}$, being the larger of the two elements, prefers a higher local coordination ( $\mathrm{CN}=16[10])$, changing the local polyhedral motifs. As Cheng and Ma [25] point out, the number of $\mathrm{Zr}$-centered motifs increases with $\mathrm{Zr}$ content, but no dominant motif, replacing the $\mathrm{Cu}$-centered FIs, can be identified.

\subsection{Shear bands and pileup}

After indentation, the deformation created in the samples with $50 \%$ and $35.5 \% \mathrm{Cu}$ concentration forms a different pattern than the one with $64.5 \% \mathrm{Cu}$. This can be observed in the von-Mises shear strain (VMSS) maps shown in Fig. 3. This figure compares the composition $\mathrm{Cu}_{64.5} \mathrm{Zr}_{35.5}$ (a-c) and $\mathrm{Cu}_{50} \mathrm{Zr}_{50}$ (d-f) at indentation depths $d=5 \mathrm{~nm}$ (a and d), $6 \mathrm{~nm}$ (b and e), and $7 \mathrm{~nm}$ (c and f). For the $\mathrm{Cu}_{64.5} \mathrm{Zr}_{35.5}$ composition, plasticity is strongly localized, i.e., it is characterized by the formation of shear bands. These already show up at intermediate indentation depths, $d=5 \mathrm{~nm}$, but intensify with deeper indentation. In the case of $\mathrm{Cu}_{50} \mathrm{Zr}_{50}$, the deformation is homogeneous and consists mostly of unorganized local shear regions called shear transformation zones (STZs). We do not show the results for the sample $\mathrm{Cu}_{35.5} \mathrm{Zr}_{64.5}$ as they are very similar to $\mathrm{Cu}_{50} \mathrm{Zr}_{50}$. This behavior is not unique to indentation; we show in the Appendix 1 that cutting the same samples results in better defined shear bands for the composition with maximum $\mathrm{Cu}$ content.

Moreover, it can be observed in Fig. 3 that the shape of the pileup is different for the two different compositions. For the $\mathrm{Cu}_{64.5} \mathrm{Zr}_{35.5}$ composition, the pileup formed features abrupt changes of the slope; these are generated when shear bands intersect the surface. In addition, the pileup features a left-right asymmetry. This asymmetry is due to the shear band that formed at the left side of the sample, which was initiated around the indenter and exited the sample at the bottom of the pileup. In contrast, the composition $\mathrm{Cu}_{50} \mathrm{Zr}_{50}$ formed a symmetric and broader pileup with a continuously changing slope.

\subsection{Shear strain, coordination, and polyhedral clusters in the deformed samples}

We analyse the deformation in more detail by measuring quantitative changes in the samples with respect to the distance from the indenter surface. In order to perform this analysis, we divide our sample into several cylindrical shells, starting at the indenter surface and then continuing toward the sample interior. For each cylindrical shell, we measure the averaged VMSS, the FI fraction, and the total number of atoms within the shell divided by the volume of the shell, i.e., the atomic density $\rho$. The cylindrical shells are separated by a radial distance of $2.77 \AA$, and their distance from the indenter surface is denoted as $r_{a}$. For this analysis, the pileup is not included. Also the region immediately adjacent to the indenter, $r_{a} \leq 0.831 \mathrm{~nm}$, is excluded, since here the
Fig. 3 Side view of the compositions a-c $\mathrm{Cu}_{64.5} \mathrm{Zr}_{35.5}$ and $\mathbf{d}-\mathbf{f}$ $\mathrm{Cu}_{50} \mathrm{Zr}_{50}$ for indentation depths a and $\mathbf{d} 5 \mathrm{~nm}$, b and $\mathbf{e} 6 \mathrm{~nm}$, and c and $\mathbf{f} 7 \mathrm{~nm}$. Atoms are colored according to their von-Mises shear strain (VMSS). Two representative shear bands are marked in subpanel (c).
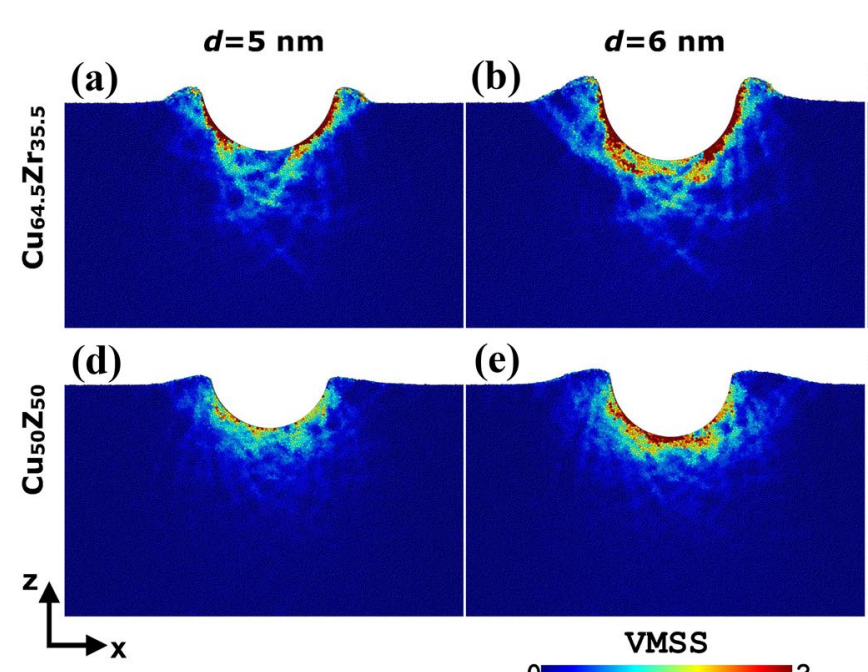

(e)



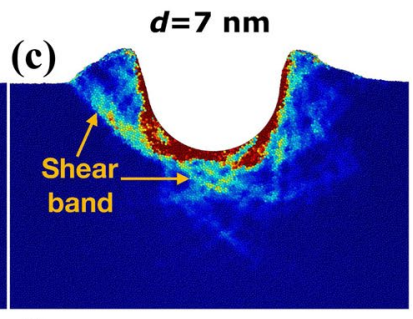

(f)

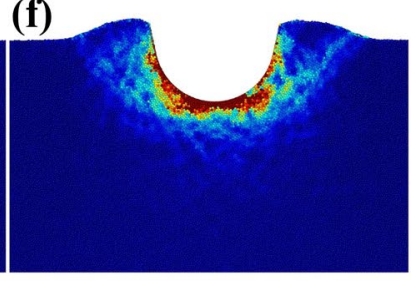


high indentation-induced compaction leads to dramatic density increases which destroys the icosahedral clusters almost entirely. The results of our analysis are displayed in Fig. 4.

It shows that the higher the $\mathrm{Cu}$ concentration, the higher the initial percentage of FI clusters, and the higher the atomic density. This has also been demonstrated in Refs. [7, 8], where the most compact structure of the glass is found around the stoichiometry where the concentration of icosahedra takes its maximum, i.e., at $75 \% \mathrm{Cu}$.

Furthermore, Fig. 4 shows that, as expected by the observations from Fig. 3, the VMSS takes its highest values around the indentation site and decays rapidly up to a distance $\sim 10 \mathrm{~nm}$. While the decline of the VMSS with distance is similar in all samples, the sample with $64.5 \%$ $\mathrm{Cu}$ experiences a slightly higher shear strain close to the indenter surface. For this composition, for a radial distance $r_{a}<5 \mathrm{~nm}$, around $8.2 \%$ of the FI clusters were destroyed by the indentation process. The FI clusters only reach their undeformed value $\sim 10 \mathrm{~nm}$ away from the indenter surface, corresponding to the point where the VMSS reaches a value close to zero. At the same time, a decrease in the atomic density can be observed at similar radial distances, with a minimum located closer to the indenter. In cutting simulations (see Appendix 1), a similar decrease in the FI clusters, and the density has been observed along the path of propagation of the shear bands. For indentation, however, the decrease in density around the indenter is rather surprising due to the type of deformation. Intuitively, an increase in the atomic density would be expected since the pressure exerted by the indenter leads to an atomic compression. Having the opposite effect indicates that the decrease in the density due to the breakage of the most compact clusters is more significant than the increase in the density created by the compression of the indenter. Additionally, the formation of the pileup creates an additional path for material to move upward, thus releasing the stress created by the indenter.
The $\mathrm{Cu}_{50} \mathrm{Zr}_{50}$ sample shows a similar behavior as the one seen for $\mathrm{Cu}_{64.5} \mathrm{Zr}_{35.5}$ in Fig. 4. However, for the former, the effects of the deformation on the FI clusters are considerable smaller, accounting for a maximum decrease of only $1.8 \%$ reached at a distance of $\sim 6.6 \mathrm{~nm}$ away from the indenter surface. Surprisingly, for the sample with the smallest $\mathrm{Cu}$ content, the opposite effect can be observed, where we observe an increase of $\sim 1 \%$ of the FI clusters around the indentation site, albeit starting from a very small level (1.7 $\%)$. The increase in the tightly coordinated FIs explains why the density decrease in this sample is relatively moderate.

Before deformation, the average coordination in the samples increases with $\mathrm{Zr}$ content, see Fig. 5, since $\mathrm{Zr}$ has a larger atomic radius than $\mathrm{Cu}$. This figure also shows how the average atomic coordination changes in the vicinity of the indenter as a function of the distance to the indenter surface, $r_{a}$. While for $\mathrm{Cu}_{35.5} \mathrm{Zr}_{64.5}$, the changes seem to be unsystematic, for $\mathrm{Cu}_{50} \mathrm{Zr}_{50}$ and in particular $\mathrm{Cu}_{64.5} \mathrm{Zr}_{35.5}$ a

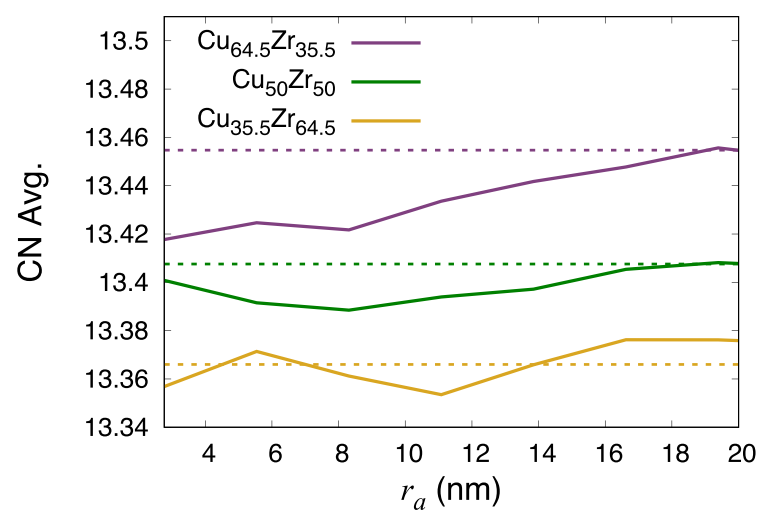

Fig. 5 Dependence of the atomic coordination number $(\mathrm{CN})$, averaged over $\mathrm{Cu}$ and $\mathrm{Zr}$, in the three samples as a function of the radial distance $r_{a}$ to the indenter surface. The dashed lines indicate the average coordination in the undeformed systems. (a) $\mathrm{Cu}_{64.5} \mathrm{Zr}_{35.5}$

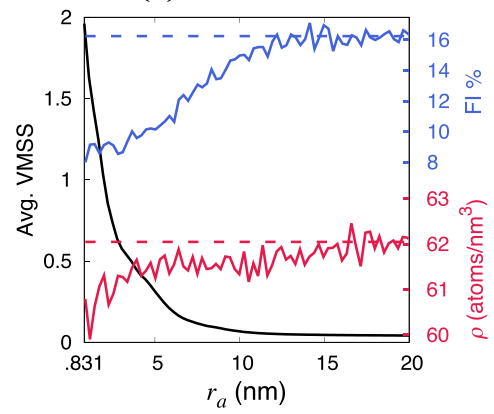

(b) $\mathrm{Cu}_{50} \mathrm{Zr}_{50}$

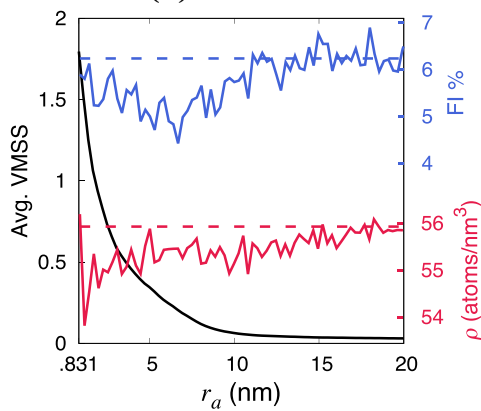

(c) $\mathrm{Cu}_{35.5} \mathrm{Zr}_{64.5}$

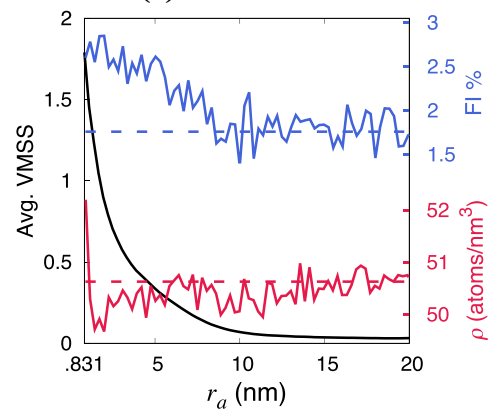

Fig. 4 Dependence of the VMSS (black), the percentage of full icosahedral (FI) clusters (blue) and the atomic density $\rho$ (red) on the radial distance $r_{a}$ to indenter surface for a $\mathrm{Cu}_{64.5} \mathrm{Zr}_{35.5}, \mathbf{b} \mathrm{Cu}_{50} \mathrm{Zr}_{50}$, and $\mathbf{c}$
$\mathrm{Cu}_{35.5} \mathrm{Zr}_{64.5}$. The values of the FI content and the density before deformation are shown by the horizontal dashed lines in the corresponding colors. Data are for full indentation, $d=7 \mathrm{~nm}$. 
clear decrease of the average coordination in the plastic zone can be observed.

We shall study this effect in more detail and also investigate the effects of the deformation on the initial motifs. For this analysis, we do not consider the list of polyhedra as detailed in Fig. 2. Rather, we mix all polyhedra with the same coordination number $(\mathrm{CN})$ and measure the local variations with respect to the distance to indenter surface, $r_{a}$. Fig. 6 shows the results of this analysis. Note that the FI clusters, $\langle 0,0,12,0\rangle$, have $\mathrm{CN}=12$. In this figure, as in Fig. 5 above, we increased the width of the radial shells to $2.7 \mathrm{~nm}$ to better average over small fluctuations. In order to study the changes that take place at the location where the maximum deformation occurs, one can use the VMSS data from Fig. 4. Thus, the main observations that can be extracted from Fig. 6 are as follows.

- The motifs with coordination number $\mathrm{CN} \geq 15$ decreased after the deformation in the three compositions.

- For $\mathrm{Cu}_{64.5} \mathrm{Zr}_{35.5}$, the annihilation of the preferred motifs close to the indentation site is more dramatic than the creation of new ones, with the deformation being mostly governed by the breakage of the motifs with $\mathrm{CN}=12$. These clusters are mainly constituted by the FIs according to Fig. 4.

- For the $\mathrm{Cu}_{50} \mathrm{Zr}_{50}$ sample, the total number of polyhedral annihilation decreased in comparison to the $\mathrm{Cu}_{64.5} \mathrm{Zr}_{35.5}$ sample. Also, the creation of the motifs with $\mathrm{CN}=13$ increases to around $1 \%$ in comparison to the $\mathrm{Cu}_{64.5} \mathrm{Zr}_{35.5}$ sample.

- A decrease of density caused by the plastic deformation is observed in all glasses. Such a density decrease corresponds to experimental [26] and previous simulational $[27,28]$ observations. The plastic motion of atoms introduces defects into the material which lower the local density; this effect is most pronounced in the best-ordered structures, i.e., in the $\mathrm{Cu}$-rich samples with their frequent icosahedral motifs.

- In the $\mathrm{Cu}_{35.5} \mathrm{Zr}_{64.5}$ sample, the population of the clusters with $\mathrm{CN}=12$ increases to above $1.5 \%$. This is different to the observations in the other two samples. Also, there is an increase of motifs with $\mathrm{CN}=13$ to $1.5 \%$ in comparison to the undeformed sample. Overall, for this composition, the creation of new clusters is faster than their annihilation.

- The deformation of the $\mathrm{Cu}_{35.5} \mathrm{Zr}_{64.5}$ sample seems to have a longer-ranged effect, as can be seen in the data for the cluster with $\mathrm{CN}=13$. In this particular case, even at a distance of $r_{a}=20 \mathrm{~nm}$, a change of $\sim 0.5 \%$ can be still observed, while for the other samples, at this distance, the pre-deformation values are reached.

Interestingly, the results described above are similar to results obtained in a cutting simulation (see Appendix 1). In any particular composition, the motifs affected in the region of maximum shear are the same in the indentation simulation and in the cutting simulation. Moreover, the percentage change is also similar in both types of simulations. This suggests that the results depend on the sample structure-in particular the initial FI content, which depends on sample preparation and relaxation as well as on stoichiometryrather than the deformation dynamics.

We conclude that plastic deformation in all glasses leads to a decrease of density. This decrease is most pronounced (up to $4 \%$ ) for high $\mathrm{Cu}$ content and is accompanied by the destruction of FIs and other highly coordinated clusters. The case of small $\mathrm{Cu}$ content, $\mathrm{Cu}_{35.5} \mathrm{Zr}_{64.5}$, shows an increase in FIs and also of other 12- and 13-fold coordinated clusters, while clusters with $\mathrm{CN} \geq 14$ are destroyed, and the density decrease is mild (2\%). (a) $\mathrm{Cu}_{64.5} \mathrm{Zr}_{35.5}$

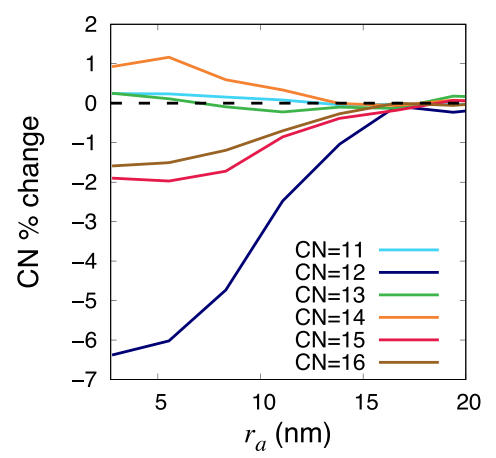

(b) $\mathrm{Cu}_{50} \mathrm{Zr}_{50}$



(c) $\mathrm{Cu}_{35.5} \mathrm{Zr}_{64.5}$

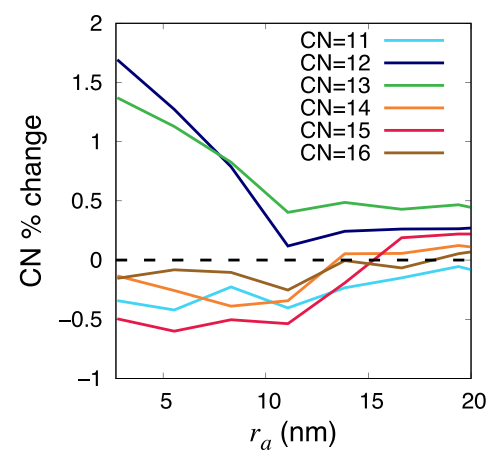

Fig. 6 Percentage change of the coordination number $(\mathrm{CN})$ as a function of the radial distance $r_{a}$ to the indenter surface for $\mathbf{a} \mathrm{Cu}_{64.5} \mathrm{Zr}_{35.5}, \mathbf{b} \mathrm{Cu}_{50}$ $\mathrm{Zr}_{50}$, and $\mathbf{c} \mathrm{Cu}_{35.5} \mathrm{Zr}_{64.5}$. Data are for full indentation, $d=7 \mathrm{~nm}$. 


\subsection{Plastic zone}

In this section, we analyse the plastic zone created by the indenter for the three different compositions.

In order to analyse the structure of the plastic zone further, we define as 'plastically active atoms' those that suffer a von-Mises shear strain above a certain threshold, which we choose here as VMSS $>0.3$ [29]. The spatial structure of these plastic zones is depicted in Fig. 7. The plastic zone appears to be more homogeneously distributed around the indenter for $\mathrm{Cu}_{50} \mathrm{Zr}_{50}$ and $\mathrm{Cu}_{35.5} \mathrm{Zr}_{64.5}$ than for $\mathrm{Cu}_{35.5} \mathrm{Zr}_{64.5}$. The inhomogeneous structure of the plastic zone is caused by the shear bands that extend out into the sample.

We determine the density of these plastically active atoms, $\rho_{a}$, as a function of the distance from the indenter surface, $r_{a}$, in a similar way to the quantities obtained in Fig. 4, see Sect. 3.3. The results are shown in Fig. 8 where, as discussed above, the data of the two cylindrical shells closest to the indenter surface are omitted. The dashed lines in Fig. 8 correspond to the densities of the undeformed system for comparison. It can be observed that close to the indenter there is a plateau in the density close to the value of the undeformed system. This means that close to the indenter almost all the atoms participate in the deformation. The density values at the plateau differ farther from the undeformed values as the $\mathrm{Cu}$ concentration increases. This is consistent with the results found in Fig. 8, where it was shown that the atomic density decreases further with higher $\mathrm{Cu}$ concentration. The plateau extends father out for smaller $\mathrm{Cu}$ concentration indicating a bigger core of the plastic zone. This finding coincides with Fig. 7, where the plastic zone appears to be more homogeneously distributed around the indenter for $\mathrm{Cu}_{50} \mathrm{Zr}_{50}$ and $\mathrm{Cu}_{35.5} \mathrm{Zr}_{64.5}$. The density of the plastic zone decays similarly for the cases $\mathrm{Cu}_{50} \mathrm{Zr}_{50}$ and $\mathrm{Cu}_{35.5} \mathrm{Zr}_{64.5}$, indicating that despite the difference in the initial atomic density, the final extensions of the plastic zones are almost identical. In the case of $\mathrm{Cu}_{64.5} \mathrm{Zr}_{35.5}$, the density of plastically active atoms decreases faster than in the other cases. However, after $\sim 7.5 \mathrm{~nm}$, the behavior changes and the density of $\mathrm{Cu}_{64.5} \mathrm{Zr}_{35.5}$

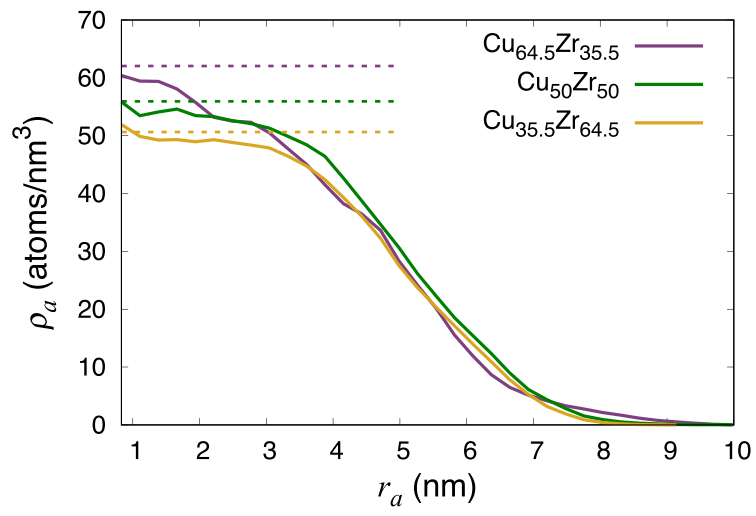

Fig. 8 Density of plastically active atoms, $\rho_{a}$, as a function of the distance from the indenter surface, $r_{a}$. The dashed lines give the atom densities of the undeformed system.

decreases more slowly than for the other two samples; this behavior is caused by the shear bands that extend out into the sample as seen in Fig. 7.

\section{Summary}

We performed molecular dynamics simulations of nanoindentation and orthogonal cutting of three samples of $\mathrm{CuZr}$ MGs to identify the differences in plasticity. Before deformation, the different compositions of the three samples showed up in a different content of SRO motifs, as was known already previously $[7,8,10,25]$ : whereas the sample with the highest $\mathrm{Cu}$ content, $\mathrm{Cu}_{64.5} \mathrm{Zr}_{35.5}$, is characterized by a high fraction of $\mathrm{Cu}$-centered FIs, the contribution of FIs shrinks with decreasing $\mathrm{Cu}$ content, while no other structural motif takes a dominating role. The average coordination number of the three samples decreases with $\mathrm{Cu}$ content.

Both nanoindentation and orthogonal cutting lead to comparable effects in the MG plasticity. Only for the highest $\mathrm{Cu}$ content, $\mathrm{Cu}_{64.5} \mathrm{Zr}_{35.5}$, plasticity is localized in shear bands, while in the glasses with lower $\mathrm{Cu}$ content, $\mathrm{Cu}_{50} \mathrm{Zr}_{50}$ and
Fig. 7 Plastic zones at maximum indentation depth $d=7$ $\mathrm{nm}$. The figure shows the data of $\mathbf{a} \mathrm{Cu}_{50} \mathrm{Zr}_{50}$ and $\mathbf{b ~ C \mathrm { Cu } _ { 3 5 . 5 }}$ $\mathrm{Zr}_{64.5}$ overlaid on the data of $\mathrm{Cu}_{64.5} \mathrm{Zr}_{35.5}$ to allow better comparison. Only atoms with VMSS $>0.3$ are shown. (a)

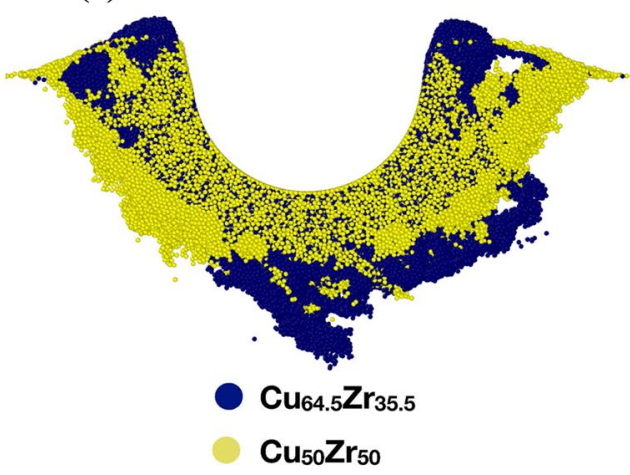

(b)

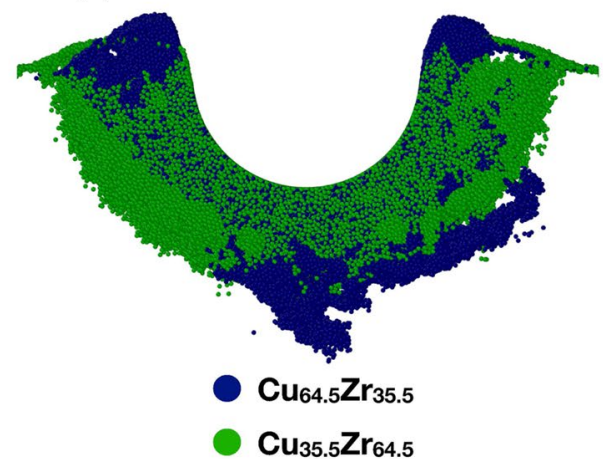


$\mathrm{Cu}_{35.5} \mathrm{Zr}_{64.5}$, STZs are generated in a homogeneous way without leading to shear localization. This feature is in agreement with the well known mechanical superiority of $\mathrm{Cu}$-rich $\mathrm{CuZr}$ glasses $[8,25]$.

In the plastic zone, the atomic density decreases. The strongest density reduction occurs in $\mathrm{Cu}_{64.5} \mathrm{Zr}_{35.5}$, where it is connected with the partial destruction of FI short-range order. With decreasing $\mathrm{Cu}$ content, the density reduction becomes less pronounced. The generation of free specific atomic volume, which is necessary for atom movement in deformation, is responsible for the density decrease. In the $\mathrm{Cu}_{64.5} \mathrm{Zr}_{35.5}$ and $\mathrm{Cu}_{50} \mathrm{Zr}_{50}$ samples, it is accompanied by a reduction in the average atom coordination. A possible coordination change in $\mathrm{Cu}_{35.5} \mathrm{Zr}_{64.5}$ could not be observed as coordination fluctuations are particularly high.

For the smallest $\mathrm{Cu}$ concentration, $\mathrm{Cu}_{35.5} \mathrm{Zr}_{64.5}$, we observe an increase in FI content during indentation. Since these FI clusters are considered most stable and are related to a more relaxed structure, our finding implies that by applying a deformation to the sample, $\mathrm{Cu}_{35.5} \mathrm{Zr}_{64.5}$ reached a more stable structure. Thus, deformation helps the $\mathrm{Cu}$-poor sample to attain a better relaxed structure. This appears to be a novel result that points in the direction of stress-induced crystallization [10, 30, 31]. In such cases, the applied stress lowers the energy barriers between different basins on the potential energy landscape thus alleviating relaxation [10].

\section{Appendix 1: Orthogonal cutting simulation}

In order to assess the generality of our findings, we perform cutting simulations in the same samples as described in the main text and analyse the plasticity found. The cutting tool is made of $\mathrm{C}$ atoms and has a rake angle of $8^{\circ}$, see Fig. 9. The tool and the sample interact via a purely repulsive short-ranged potential. For further information on this type of simulation, we refer the readers to Refs. [27, 32-34]. We cut the MGs at a depth of $7 \mathrm{~nm}$ to a total cutting length of $l=20 \mathrm{~nm}$ with a cutting velocity of $20 \mathrm{~m} / \mathrm{s}$.

Side views of the VMSS in the cut samples at $l=20 \mathrm{~nm}$ are shown in Fig. 10a-c for the three compositions. It can be observed that the chip has a prismatic shape in all the cases; however, its thickness increases and its height decreases with decreasing $\mathrm{Cu}$ content. The primary shear zone (PSZ), where the shear bands are created, is the plane extending from the tool edge to the surface of the sample. Therefore, the shear bands that form in the chip are parallel to each other. All these features agree with previous findings discussed in Refs. [27, 32-34].

Moreover, the intensity of the colors of Fig. 10a-c suggests that the shear bands formed in the chip of the $\mathrm{Cu}_{64.5}$ $\mathrm{Zr}_{35.5}$ sample are better defined than in the other two compositions. This is confirmed by quantifying the VMSS in

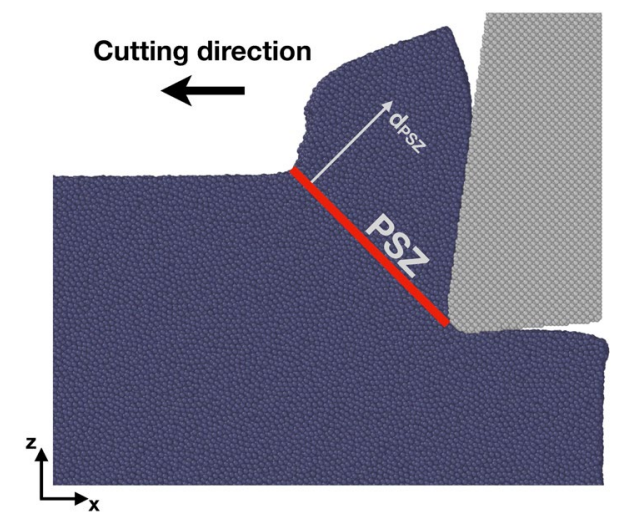

Fig. 9 Schematic setup of the cutting simulations. The cutting tool is shown in gray, and the primary shear zone (PSZ) in red. Plasticity in the generated chip is analyzed in dependence of the distance to the PSZ, $d_{\mathrm{PSZ}}$.

the chip as shown in Fig. 10d-e. It can be observed that for $\mathrm{Cu}_{64.5} \mathrm{Zr}_{35.5}$, Fig. 10d, the peaks in the VMSS-which indicate the position of the shear bands-are better distinguishable than in the other two cases (Fig. 10e and f).

The analysis shown in this figure was performed by slicing the chip in layers parallel to the PSZ with a thickness of $2.77 \AA$. Fig. $10 \mathrm{~d}-\mathrm{f}$ shows the data of the averaged VMSS per layer, the FI content and the density, $\rho_{l}$, as a function of the distance from the PSZ, $d_{\mathrm{PSZ}}$, see Fig. 9. Here, the density $\rho_{l}$ is calculated as the number of atoms in the layer divided by its length; it represents a layer density rather than the volumetric density that was shown in Fig. 2.

The changes in $\rho_{l}$ and FI fraction in Fig. 10d-f show similar trends as in Fig. 2. $\rho_{l}$ decreases where the shear strain increases, i.e., in the shear bands. Most interestingly, as in the case of indentation, the FI cluster fraction decreases where the deformation takes place for $\mathrm{Cu}_{64.5} \mathrm{Zr}_{35.5}$ and $\mathrm{Cu}_{50}$ $\mathrm{Zr}_{50}$, while it increases for the $\mathrm{Cu}_{35.5} \mathrm{Zr}_{64.5}$.

Finally, we analyse the changes in the motifs according to their coordination number in the chip as a function of the distance from the PSZ, $d_{\mathrm{PSZ}}$ in Fig. 11. To generate this figure, we increased the layer width to $2.7 \mathrm{~nm}$, similar to the procedure to create Fig. 6. While this does not allow us to study the effects in the individual shear bands formed - since these are too narrowly spaced - we observe very similar results to the ones found in Fig. 6. For both types of deformation, the same motifs are being affected in the shear zones, as was discussed in detail in Sect. 3.3. This is the case for all the three samples.

We conclude that the changes in the plasticity with the composition of the MG found for indentation-induced plasticity hold equally for plasticity induced by a cutting process.

Acknowledgements Simulations were performed at the High Performance Cluster Elwetritsch (RHRK, TU Kaiserslautern, Germany) 


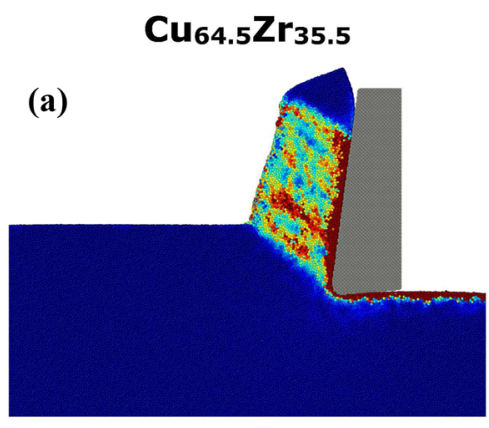

(d)

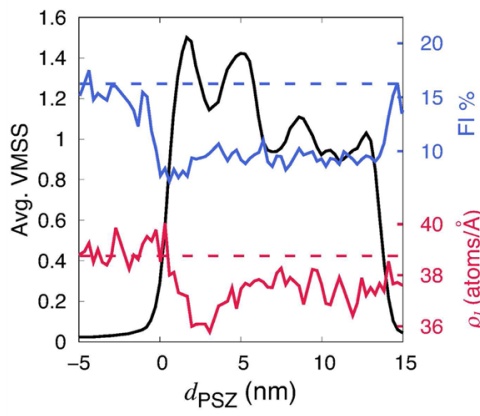

$\mathrm{Cu}_{50} \mathrm{Zr}_{50}$

(b)

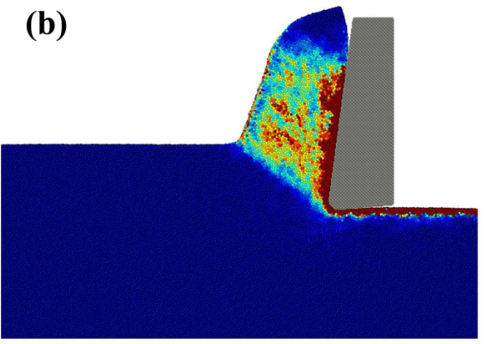

(e)

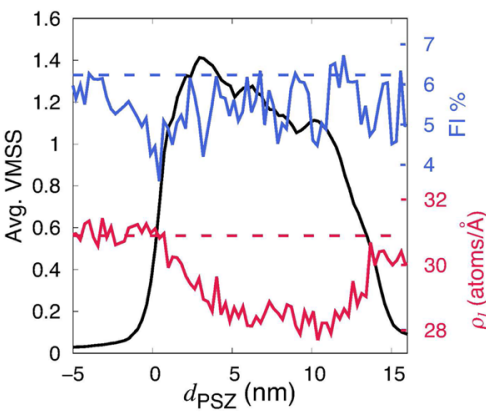

$\mathrm{Cu}_{35.5} \mathrm{Zr}_{64.5}$

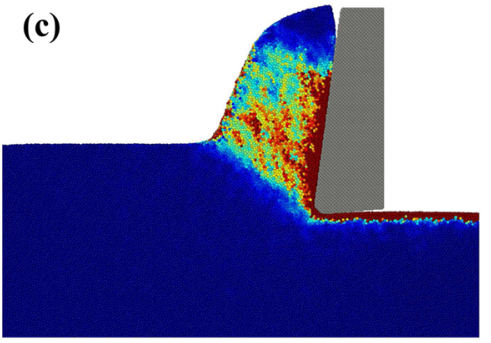

(f)

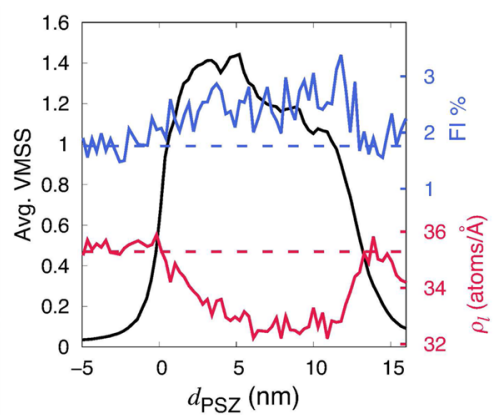

Fig. 10 Top row: Side view of the compositions a $\mathrm{Cu}_{64.5} \mathrm{Zr}_{35.5}, \mathbf{b} \mathrm{Cu}_{50}$ $\mathrm{Zr}_{50}$, and $\mathbf{c} \mathrm{Cu}_{35.5} \mathrm{Zr}_{64.5}$ for the cutting simulation at cutting length $l=20 \mathrm{~nm}$. Atoms are colored according to their von-Mises shear strain (VMSS). Bottom row: d-f Dependence of the VMSS (black), full icosahedra (FI) clusters percentage (blue), and density (red), $\rho_{l}$, as a function of the distance to the PSZ, $d_{\mathrm{PSZ}}$. The horizontal dashed lines give the values of the undeformed system. (a) $\mathrm{Cu}_{64.5} \mathrm{Zr}_{35.5}$



(b) $\mathrm{Cu}_{50} \mathrm{Zr}_{50}$

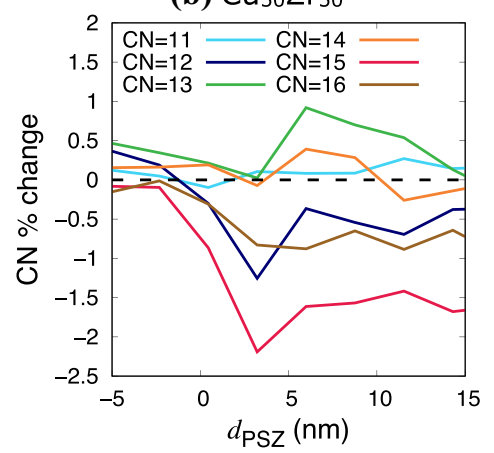

(c) $\mathrm{Cu}_{35.5} \mathrm{Zr}_{64.5}$



Fig. 11 Cutting simulation: Percentage change of the coordination number $(\mathrm{CN})$ as a function of the distance from the primary shear zone, $d_{\mathrm{PSZ}}$, for $\mathbf{a} \mathrm{Cu}_{64.5} \mathrm{Zr}_{35.5}, \mathbf{b ~ C u} \mathrm{Cu}_{50}$, and $\mathbf{c} \mathrm{Cu}_{35.5} \mathrm{Zr}_{64.5}$. Data are for a cutting length of $l=20 \mathrm{~nm}$.

and the HPC-IBEROGUN Center of the Universidad Tecnológica de Panamá. R.E.P. had support from SENACYT through projects FID2016-275 and EIE-2018-16; and through the Sistema Nacional de Investigación (SNI) of SENACYT (Contract No. 159-2018). R.E.P. also thanks the Universidad Tecnológica de Panamá for their extensive support and for the use of their CIHH-group HPC-Cluster-Iberogun. He acknowledges support by the NVIDIA Corporation for the donation of the Titan Xp GPU used for this research.
Funding Open Access funding enabled and organized by Projekt DEAL.

Open Access This article is licensed under a Creative Commons Attribution 4.0 International License, which permits use, sharing, adaptation, distribution and reproduction in any medium or format, as long as you give appropriate credit to the original author(s) and the source, 
provide a link to the Creative Commons licence, and indicate if changes were made. The images or other third party material in this article are included in the article's Creative Commons licence, unless indicated otherwise in a credit line to the material. If material is not included in the article's Creative Commons licence and your intended use is not permitted by statutory regulation or exceeds the permitted use, you will need to obtain permission directly from the copyright holder. To view a copy of this licence, visit http://creativecommons.org/licenses/by/4.0/.

\section{References}

1. C.A. Schuh, T.C. Hufnagel, U. Ramamurty, Acta Materialia 55, 4067 (2007)

2. A.L. Greer, Science 267, 1947 (1995)

3. Y.Q. Cheng, E. Ma, Appl. Phys. Lett. 93, 051910 (2008)

4. Z.D. Sha, Y.P. Feng, Y. Li, Appl. Phys. Lett. 96, 061903 (2010)

5. J. Zemp, M. Celino, B. Schönfeld, J.F. Löffler, Phys. Rev. Lett. 115, 165501 (2015)

6. R. Soklaski, Z. Nussinov, Z. Markow, K.F. Kelton, L. Yang, Phys. Rev. B 87, 184203 (2013)

7. M. Wakeda, Y. Shibutani, S. Ogata, J. Park, Intermetallics 15, 139 (2007)

9. Y. Q. Cheng, J. Ding, E. Ma, Mater. Res. Lett. 1, 3 (2013)

8. K.-W. Park, J. il Jang, M. Wakeda, Y. Shibutani, J.-C. Lee, Scripta Mater. 57, 805 (2007)

10. E. Ma, Nature Mater. 14, 547 (2015)

11. Z.W. Wu, M.Z. Li, W.H. Wang, K.X. Liu, Phys. Rev. B 88, 054202 (2013)

12. A.L. Greer, Y.Q. Cheng, E. Ma, Mater. Sci. Eng. R Rep. 74, 71 (2013)

13. R. Maaß, J.F. Löffler, Adv. Funct. Mater. 25, 2353 (2015)

14. D. Şopu, A. Stukowski, M. Stoica, S. Scudino, Phys. Rev. Lett. 119, 195503 (2017)

15. J.-O. Krisponeit, S. Pitikaris, K.E. Avila, S. Küchemann, A. Krüger, K. Samwer, Nat. Commun. 5, 3616 (2014)

16. C. Tang, H. Peng, Y. Chen, M. Ferry, J. Appl. Phys. 120, 235101 (2016)

17. A.J. Cao, Y.Q. Cheng, E. Ma, Acta Mater. 57, 5146 (2009)
18. K.E. Avila, S. Küchemann, I. Alabd Alhafez, M. Urbassek, Materials 12, 1477 (2019a)

19. K.E. Avila, S. Küchemann, I. Alabd Alhafez, H.M. Urbassek, Tribol. Int. 139, 1 (2019b)

20. S. Plimpton, J. Comput. Phys. 117, 1 (1995) http://lammps.sandia. gov/

21. M.I. Mendelev, D.J. Sordelet, M.J. Kramer, J. Appl. Phys. 102, 043501 (2007)

22. C.L. Kelchner, S.J. Plimpton, J.C. Hamilton, Phys. Rev. B 58 , 11085 (1998)

23. A. Stukowski, Model. Simul. Mater. Sci. Eng. 18, 015012 (2010) http://www.ovito.org/

24. F. Yonezawa, S. Nosé, S. Sakamoto, Zeitschrift für Physikalische Chemie 156, 77 (1988)

25. Y.Q. Cheng, E. Ma, Progress Mater. Sci. 56, 379 (2011)

26. C. Liu, V. Roddatis, P. Kenesei, R. Maaß, Acta Mater. 140, 206 (2017)

27. K.E. Avila, S. Küchemann, H.M. Urbassek, J. Non-Cryst. Solids 566, 120882 (2021a)

28. K.E. Avila, V.H. Vardanyan, H.M. Urbassek, Eur. Phys. J. B 94, $152(2021 b)$

29. K.E. Avila, S. Küchemann, H.M. Urbassek, J. Non-Cryst. Solids 523, 119593 (2019c)

30. Z. Yan, K. Song, Y. Hu, F. Dai, Z. Chu, J. Eckert, Sci. Rep. 6, 19358 (2016)

31. Y. Mao, J. Li, Y.-C. Lo, X. Qian, E. Ma, Phys. Rev. B 91, 214103 (2015)

32. K.E. Avila, S. Küchemann, I. Alabd Alhafez, H.M. Urbassek, J. Appl. Phys. 127, 115101 (2020a)

33. K.E. Avila, V.H. Vardanyan, I. Alabd Alhafez, M. Zimmermann, B. Kirsch, H.M. Urbassek, J. Non-Cryst. Solids 550, 120363 (2020b)

34. V.H. Vardanyan, K.E. Avila, S. Küchemann, H.M. Urbassek, Comput. Mater. Sci. 192, 110379 (2021)

Publisher's Note Springer Nature remains neutral with regard to jurisdictional claims in published maps and institutional affiliations. 